\title{
El mal singular frente al bien plural en el Ms. K-IIl-4 (Libro de Apolonio, Vida de Santa María Egipciaca, Libro de los tres reyes de Oriente)
}

\author{
Singular evil versus plural good in Ms. Esc. K-III-4t (Libro de Apolonio, Vida de \\ Santa María Egipciaca, Libro de los tres reyes de Oriente)
}

(D) Carina Zubillaga carinazubillaga@hotmail.com

Seminario de Edición y Crítica Textual. Instituto de Investigaciones Bibliográficas y Crítica Textual. Universidad de Buenos Aires / CONICET, Argentina

Recepción: 30 Octubre 2020

Aprobación: 24 Abril 2021

Publicación: 03 Mayo 2021

Cita sugerida: Zubillaga, C. (2021). El mal singular frente al bien plural en el Ms. K-III-4 (Libro de Apolonio, Vida de Santa María Egipciaca, Libro de los tres reyes de Oriente). Olivar, 21(33), e098. https://doi.org/10.24215/18524478e098
Resumen: El Ms. K-III-4 de la Biblioteca de San Lorenzo de El Escorial reúne tres poemas del temprano siglo XIII que presentan numerosos rasgos comunes, en particular temáticos, a pesar de sus diferencias. Las asociaciones entre unos y otros los acercan en la dinámica compilatoria del códice, a pesar de que la crítica previamente los distinguiera como representantes del "mester de clerecía" y del "mester de juglaría" hispánicos debido a su metro estilizado (Libro de Apolonio) o su metro popular (Vida de Santa María Egipciaca y Libro de los tres reyes de Oriente). La ejemplaridad cristiana es el eje que permite unificarlos, mediante la oposición bien-mal que configura cada poema y de la identificación de las formas del bien con lo colectivo y de las manifestaciones del mal, en contraposición, con la individualidad.

Palabras clave: Mal singular, Bien plural, Ética cristiana, Compilación manuscrita.

Abstract: The manuscript K-III-4 brings together three poems from the early thirteenth century that present numerous common features, particularly thematic, despite their differences. The associations between each other bring them closer, despite the fact that critics initially considered them as representatives of "mester de clerecía" and "mester de juglaría" due to their stylized verse (Libro de Apolonio) or its popular verse (Vida de Santa María Egipciaca and Libro de los tres reyes de Oriente). Christian exemplarity is the axis that allows them to be unified, through the good-evil opposition that shapes each poem and the identification of the forms of good with the collective and of the manifestations of evil to individuality.

Keywords: Singular evil, Plural good, Christian ethics, Manuscript compilation. 


\section{LA OPOSICIÓN EJEMPLAR BIEN-MAL Y LA IDENTIDAD TEXTUAL DEL Ms. Esc. K-III-4}

Los tres poemas narrativos de principios del siglo XIII que componen el Ms. K-III-4 de la Biblioteca de San Lorenzo de El Escorial comparten una ética cristiana que progresa, con el avance de los relatos, hacia formas de santidad tan extremas como la historia de una prostituta penitente y la propia infancia y muerte de Cristo como modelos ejemplares. ${ }^{1}$ A pesar de esta progresión y de la diferencia genérica y métricoestrófica entre el Libro de Apolonio (una historia de aventuras de materia antigua escrita en "cuaderna vía") y la Vida de Santa María Egipciaca y el Libro de los tres reyes de Oriente (de temática religiosa y compuestos en pareados irregulares), los relatos presentan numerosas convergencias; entre ellas, tal vez la principal sea la oposición como recurso básico de configuración textual, ya que el antagonismo bien-mal constituye la base que posibilita y orienta el desarrollo narrativo de cada una de las historias.

Además de la oposición como recurso reiterado en la configuración de los relatos que integran el Ms. Esc. K-III-4, es posible plantear como hipótesis inicial del presente trabajo la identificación del bien con manifestaciones plurales en los textos, ya sea a través de personajes o situaciones colectivas que refieren a la idea de familia como núcleo básico de la sociedad cristiana que se presenta como ideal textual; el mal, entre tanto, se asocia a lo individual que se aparta de ese modelo social deseable. La individualidad, en este sentido, asume en las historias del manuscrito un carácter que permite su identificación con la marginalidad y la exclusión social.

La sociedad medieval, organizada a partir de la compartimentación de estamentos, privilegia por su constitución misma lo grupal sobre lo individual. En la sociedad feudal, como establece Segura Graiño, "el individuo no cuenta" (2001, p. 209). No es que el individuo no importe, ciertamente, sino que es su pertenencia a un grupo, su identidad grupal, lo que lo define y determina su lugar social. Esa subordinación de lo individual a lo grupal es lo que posibilita asociar las formas del bien, o lo deseable, a la integración social, en tanto las manifestaciones del mal asumen un carácter singular que, de acuerdo con la ética cristiana medieval, subraya el pecado como su expresión primaria. En este sentido, indagar en las numerosas formas con que el bien plural y el mal individual se presentan en las historias de un códice antológico como el K-III-4 permitirá dar cuenta de la ejemplaridad planteada por este tipo de historias y, asimismo, por la dinámica de su compilación conjunta, en tanto representaciones de un ideal social tendiente a un orden aglutinante que intenta reproducir internamente aquello a lo que aspira o que intenta promover en forma externa.

\section{LA HEROICIDAD FAMILIAR Y LAS REPRESENTACIONES COLECTIVAS DEL BIEN EN EL LIBRO DE APOLONIO}

A pesar de que durante la mayor parte del relato Apolonio, su esposa Luciana y su hija Tarsiana están en verdad separados, es la idea de la familia como núcleo social fundante la que caracteriza la heroicidad del Libro de Apolonio. La familia como unidad sufrirá numerosos obstáculos, siendo el principal la pérdida de unos y otros, justamente porque la prueba heroica consistirá en la puesta en práctica singular de las virtudes que los representan antes como familia cristiana que como individuos; prueba de ello, fundamentalmente, es la duplicación de las aventuras de Apolonio y Tarsiana, por un lado, y de Luciana y Tarsiana, por el otro, desarrollándose de esa forma las variantes masculina y femenina, respectivamente, de virtudes como la cortesía, la humildad y la castidad. $^{2}$

La prueba heroica de Apolonio, representada en el texto por los sucesivos naufragios que lo llevan de ciudad en ciudad y de una situación de pérdida a otra mayor, se reproduce en su hija Tarsiana concentrada básicamente en su naturaleza femenina, por lo que es la virtud de la castidad la que distingue su prueba: secuestrada por unos piratas, la joven es vendida al dueño de un prostíbulo que pondrá precio a su virginidad; son los conocimientos de Tarsiana, ligados al aprendizaje de las artes liberales, los que la llevan a afrontar 
los embates a partir de la palabra y de la música como instrumentos de superación. A semejanza de su padre Apolonio, la formación de Tarsiana en el trivium yel cuadrivium destaca su uso de la palabra -sobre todo, cifrado en las adivinanzas o enigmas lingüísticos en los que ambos son expertos- y de la música como vehículos de defensa virtuosa; esos conocimientos son puestos en práctica como oficios que les permiten a ambos demostrar de manera efectiva el saber teórico que poseen -Apolonio como maestro de música de Luciana en la corte de Pentápolis y la joven como juglaresa en el mercado de Mitilene-. ${ }^{3}$

La identificación femenina de Luciana y Tarsiana, por otra parte, que suma la identidad de género a la familiar, permite postular en la hija virtudes propias de la madre, también apreciables en el manejo lingüístico de enigmas verbales como las adivinanzas ${ }^{4}$-no olvidemos que Luciana declara su amor por Apolonio en una enigmática carta dirigida a su propio padre ("La carta diziá esto, sópola bien dictar: / que con el pelegrino queriá ella casar / que con el cuerpo solo estorçió de la mar”, 223b-d), ${ }^{5}$ en tanto Tarsiana se reencuentra con Apolonio a través de unas adivinanzas que los revelan como padre e hija-, pero sobre todo en la defensa de su castidad cifrada en la confianza en el auxilio divino y en la oración como vehículo de esa confianza. Su identificación, en este sentido, las excede como madre e hija y las equipara a las mártires cristianas que defienden su castidad; ${ }^{6}$ baste recordar la reclusión de Luciana en un monasterio hasta el reencuentro con su esposo ("Por amor que toviese su castidat mejor, / fiziéronle un monesterio do visquiese seror", 324ab) y el ruego de Tarsiana a punto de ser asesinada por Teófilo, en el cual esa referencia al martirio se explicita directamente:

Enclinóse la dueña, començó de llorar:
"Señor, dixo, que tienes el sol a tu mandar
e fazes a la luna creçer e enpocar,
Señor, tú me acorre por tierra o por mar.
Só en tierras ajenas, sin parientes criada,
la madre perdida, del padre non sé nada;
yo, mal non meresciendo, he a ser martiriada;
Señor, quando lo tú sufres só por ello pagada.
Señor, si la justiçia quisieres bien tener,
si yo non lo merezquo por el mio mereçer,
algún consejo tienes para mi acorrer,
que aqueste traidor non me pueda vençer". (381-383)

El trío familiar del Libro de Apolonio conformado por el héroe, Luciana y Tarsiana funciona como tal aunque no estén juntos, ya que los comportamientos, actitudes y virtudes que cada uno demuestra de manera singular se asientan en la identidad familiar que los configura socialmente y que guía esas conductas. Apolonio nunca deja de comportarse como esposo de Luciana y como padre de Tarsiana en la continuidad narrativa, incluso creyendo que ambas han muerto. Sufriendo la muerte aparente de Luciana, deja a Tarsiana recién nacida al cuidado de Estrángilo y Dionisa para partir a Egipto como peregrino, tal vez consciente de la pérdida de la estructura familiar -debido a la desaparición de su esposa, a quien cree muerta sin estarlo- que intenta reemplazar entonces con los huéspedes de Tarso como familia sustituta. Al regresar, muchos años después, Dionisa le anuncia a Apolonio la muerte de Tarsiana -en la que ella cree, a pesar de que tampoco la joven está muerta-; él, sin embargo, no puede llorar frente a su supuesta tumba, dudando entonces de la verdad del deceso, como solo un padre podría hacerlo: 
non pudo echar lágrima por nenguna misión.

Tornó contra si mismo, començó de asmar:

“Ay, Dios!, ¿qué puede esta cosa estar?

Si mi fja Tarsiana yoguiesse en este logar,

non devién los mis ojos tan en caro se partir.

Asmo que todo aquesto es mentira provada, non creyo que mi fja aqui es soterrada;

mas o me la han vendida o en mal logar echada.

Seya, muerta o biva, a Dios acomendada". (448-450)

Del mismo modo, tampoco Tarsiana deja de comportarse como hija de Apolonio y de Luciana, a pesar del desconocimiento de su propia historia hasta su juventud; en su caso, son principalmente sus acciones y conductas, que reproducen otras propias de sus padres, las que permiten ver en ella esa familia fundante que recién conocerá al final de la historia. ${ }^{7}$ Solo una vez que se da el reencuentro familiar, la joven conformará su propia familia y será ella misma esposa y madre. Luciana, por otra parte, se convierte llamativamente en abadesa perdidos su esposo y su hija; la extensión de su imagen materna a la comunidad que logra conformar en esa abadía resulta innegable cuando recupera a su familia, revelándose en especial en su cuidado maternal de las monjas y la consiguiente tristeza de ellas por su partida: "Por la çibdat de Effesio corrié grant alegría, / avién con esta cosa todos plazentería; / mas lloravan las dueñas dentro en la mongía, / ca se temién de la señora que se queriá ir su vía" (593).

Además de la figura triádica de la familia protagonista del Libro de Apolonio, existen representaciones colectivas -en especial, los núcleos ciudadanos- que responden como grupo a favor del orden social constituido, así como algunas parejas que también funcionan de manera semejante. De esos binomios, tal vez el más interesante de analizar sea el del médico y su discípulo que encuentran en Éfeso el cuerpo aparentemente sin vida de Luciana y la sanan de su dolencia. Es efectivamente el maestro quien halla el féretro de la mujer en la costa y lo hace trasladar a su hogar; allí, al preparar el cuerpo para su entierro, su discípulo descubre que Luciana aún está viva y gracias a sus conocimientos logra curarla, en representación de la aplicación práctica del saber personalizada asimismo tanto por Apolonio como por Tarsiana, aunque con respecto a otros saberes.

La relación maestro-discípulo es planteada textualmente como un sucedáneo de la relación padre-hijo, como establece con claridad el médico al dirigirse al aprendiz:

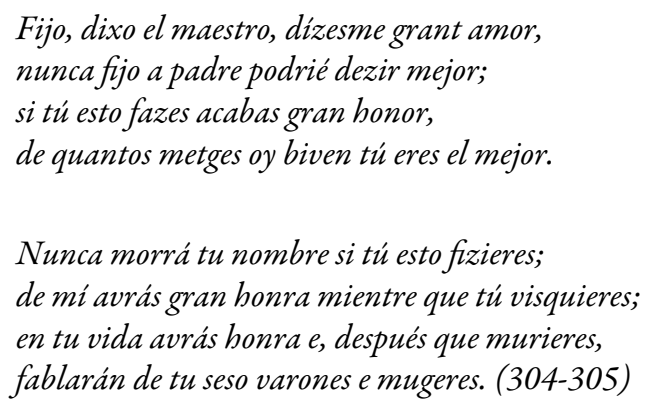

La comparación de esa relación entre el docente y su mejor alumno con una relación parental se suma a la idea de la trascendencia a partir de la honra para dar cuenta, sin lugar a duda, de la sustitución generacional implícita en la curación de Luciana, más allá de cualquier lucimiento individual. El binomio se integra en esta misma idea de recambio y trascendencia del saber y del obrar concreto del conocimiento, como práctica en este caso médica, ya que su labor se concibe a través del aprendizaje y como una continuidad que, como 
la vida misma, se asienta en el traspaso de generaciones y su importancia para la integridad familiar y más ampliamente social.

La asociación familiar, asimismo, se reproduce en la naturaleza doméstica de la escena de la curación de Luciana, ya en la casa del discípulo; el cuidado se traduce en la comodidad del hogar, dado por el fuego acogedor ("fizo fer grandes fuegos de leña trasecada, / que non fiziesen fumo nin la calor desaguisada", 306cd), ropajes apropiados ("fizo poner el cuerpo en el suelo barrido, / en una riqua colcha, en un almatraque batido", $307 \mathrm{ab}$ ) y el paso a paso posterior de la sanación del padecimiento. ${ }^{8}$ Una vez acabado el proceso, las palabras del médico remarcan esa asociación familiar que caracteriza la escena, ofreciéndose a servir a la mujer como si fuera su madre: "Yoguiésedes folgada, yo ál non vos rogaría, / yo vos faré serviçio como a madre mía" (319ab).

Una integración semejante, en función del orden social instituido, también se da en los concejos ciudadanos del poema, tanto el de Mitilene como el de Tarso. En Mitilene, el concejo determina ajusticiar a pedradas al dueño del prostíbulo en el que se encontraba Tarsiana: "moviósse el conçejo como que sañudazo; / fueron al traidor, echáronle el laço, / matáronlo a piedras como a mal rapaço” (567b-d). La acción conjunta se remarca en un plural integrador que decide tanto matar al hombre ("todos por una boca dieron esta respuesta", 566a) como luego erigirle una estatua de oro a Apolonio y su hija, en recordatorio del suceso, en medio del mercado ("tóvosse el conçejo del rey por adebdado, / ca por verdat aviéles fecho bien aguisado; / fablaron quel' fiçiessen gualardón señalado”, 570a-c). En Tarso, también el concejo actúa como una unidad que determina -frente al pedido de Apolonio- impartir justicia por el intento de asesinato de Tarsiana llevado a cabo por Teófilo, pero planificado por Dionisa. Ante el concejo como colectivo se presentan las pruebas ("fue luego la mentira en conçejo provada, / qua levantósse Tarssiana do estava assentada", 608ab), se suceden los testimonios ("por provar bien la cosa, la verdat escobrir, / mandaron a Teóffilo al conçejo venir", 609ab), se llega a un veredicto ("fue ant'el conçejo la verdat mesturada", 610a) y finalmente se concreta lo decidido ("non alongaron plazo nin le dieron vagar; / fue luego Dionisa levada a quemar, / levaron al marido desende a enforquar", 611a-c), en un proceso judicial donde ni una voz se distingue de otra ni se individualiza la acción comunitaria.

El bien se integra de manera grupal, como demuestra la pareja médica o, de manera más extendida, el accionar de los concejos ciudadanos de Mitilene y Tarso. El mal, por el contrario, está individualizado a pesar de que varios concurran en el desarrollo de una empresa maligna. Esto se evidencia, claramente, en el accionar de Dionisa, Estrángilo y Teófilo en el intento de asesinato de Tarsiana; diferente e individual será su contribución al plan, así como distinto será asimismo el castigo que cada uno de ellos reciba.

La principal representación del mal en el intento de asesinar a Tarsiana es la de Dionisa, porque es quien planifica su muerte, sin motivos y con el agravante de que es ella quien más debiera haber cuidado a la joven, dejada a su cargo por Apolonio antes de partir a Egipto. La asociación del mal planificado con el pecado resulta evidente en la falta de motivación específica de ese intento de asesinato, que solo obedece a los celos que las virtudes de Tarsiana despiertan en Dionisa y a la codicia de sus bienes, tanto intelectuales como más específicamente materiales:

Por poco que de enbidia non se queriéperder,
consejo del diablo óvolo a prender;
todo en cabo ovo en ella a cayer;
esta boz Dionisa hóvola a saber.

Asmava que la fiziese a escuso matar, ca nunqua la vernié el padre a buscar; el aver que le diera podérselo ie lograr, non podrié en otra guisa de la llaga sanar. 
"Si esta moça fuese de carrera tollida, con estos sus adobos que la fazen vellida

casaria mi fija, la que hove parida". (368-370)

La asociación de Dionisa con el pecado de la codicia, considerado en la Edad Media la raíz de los demás pecados, enfatiza la identificación del mal básicamente con lo femenino - mediante la mención explícita del consejo del diablo que la mujer atiende- y otras tantas referencias a ella como falsa, traidora y, en síntesis, malvada; la vinculación de la figura de Dionisa con la de la madrastra refuerza, además, la conexión de lo femenino con lo brujesco y lo malévolo ligado al pecado en general. Esta asociación está subrayada en el texto por el silencio acerca de la actitud de Estrángilo al respecto, que parece no participar directamente del plan de asesinar a Tarsiana, concentrándose de esa forma toda la responsabilidad de la ideación y planificación en el rol femenino de la pareja que debería haber protegido a Tarsiana como sustitutos de sus padres.

Teófilo, por otra parte, es el mero ejecutor de las órdenes de Dionisa; una figura más asociada al crimen que al pecado, en este sentido, que ni siquiera llega a cumplir la tarea asignada por darle a la joven el espacio para la oración que finalmente la salvará. Esa actitud será la que determinará un castigo muy diferente al de Dionisa y Estrángilo, debido a que la asociación en este caso con el componente religioso será declaradamente positiva, en lugar de la negativa de Dionisa con el pecado y de la complicidad por omisión de Estrángilo: "Dieron a Teófilo mejorada raçión / porque le dio espaçio de fer oraçión; / dexáronlo a vida e fue buen gualardón, / de cativo que era diéronle quitación" (612).

De esta manera, si bien el mal singular no está asociado únicamente a lo femenino en el Libro de Apolonio, sí está específicamente relacionado con el pecado y su manifestación y, por ello, enfocado de manera privilegiada en las mujeres. Dionisa, en quien recae el pecado de la codicia, se presenta vinculada a la figura tradicional de la madrastra malvada, remarcándose sus características femeninas. La lujuria en tanto pecado femenino también se sugiere inicialmente en el texto, ya que aunque es Antíoco el culpable del pecado del incesto con su hija, la princesa acepta la situación impuesta, a pesar de ser una víctima; tal vez por ello recibe el mismo castigo que su padre, ya que ambos son ajusticiados, resaltándose incluso la asociación del pecado con la provocación femenina al narrarse la muerte: "Dil' que es Antioco muerto e soterrado, / con él murió la fija quel' dio el pecado, / destruyólos a amos un rayo del diablo" (248a-c). Esta muerte, debido a un rayo, es semejante al ajusticiamiento de Dionisa, que es quemada, en una nueva comparación textual con el fuego purificador del pecado, esencialmente del pecado femenino.

\section{El bien Comunitario frente a la lujuria femenina en la Vida DE Santa María EGIPCIACA}

El pecado de la lujuria atribuible esencialmente a la mujer, y su relación con la manifestación del mal individual y su carácter marginal y asocial, incluso antisocial, sugerido previamente en las referencias a la maldad femenina en el Libro de Apolonio, se desarrolla como temática ya por extenso en la Vida de Santa María Egipciaca, el segundo poema que integra el códice K-III-4.

La historia de esta pecadora arrepentida se narra estructuralmente a partir de su vida de pecado, en la primera parte del poema, y su posterior arrepentimiento y penitencia, en la segunda parte; esas secciones del texto están retratadas cronológicamente por la juventud pecadora de la mujer y su posterior vejez penitente y condensan el mal del pecado, al principio, opuesto al bien de la gracia salvífica del final. En este sentido, la adscripción religiosa cristiana completa y declarada, al tratarse de una hagiografía, privilegia la dinámica de la oposición entre el mal y el bien, el pecado y la virtud, como una contienda propia de la humanidad y pasible de ser representada en el marco de la propia vida, como sucede con María de Egipto. La Egipciaca, de esta forma, resulta una figura paradigmática, prototipo de las prostitutas penitentes cuya devoción se afianza a fines del siglo XII y manifiestan, con su ejemplo, la posibilidad cristiana de la redención. 
La Vida de Santa María Egipciaca principia, de este modo, con la narración de la juventud lujuriosa de esta mujer, con el detalle descriptivo de su retrato y el recuento más detallado aún de su conducta como prostituta en Alejandría. Una vez que parte de su hogar, constreñida por las limitaciones familiares, María arriba a Alejandría y decide ejercer allí la prostitución. La familia obra claramente como un límite para el pecado de la joven, lo que se esclarece en su indiferencia frente al sufrimiento de sus padres ("Non preçiava su castigamiento / más que si fuesse un viento", 103-104; "La madre assí la castigava / e de sus ojos llorava. / María poco lo preçiava”, 123-125) y una conducta lujuriosa extrema, que se sugiere alcanza incluso a sus propios parientes: "A sus parientes se dava, / a todos se baldonava" (95-96). Esta traducción hispánica que en nada se corresponde con el original francés del que proviene la historia ("De dous parens ne se gardoit, / a tos homes s'abandonoit", $71-72)^{10}$ probablemente se relacione con la referencia al incesto como epítome de la lujuria presente en el Libro de Apolonio, el relato que precede a esta hagiografía en el Ms. K-III-4.

De acuerdo con el principio de la narración de su vida, es efectivamente el pecado de la lujuria lo que distingue a la joven pecadora, que una vez en Alejandría vehiculiza sus apetitos lujuriosos ejerciendo la prostitución. En este sentido, Beresford señala que es la lujuria la que prima sobre la prostitución como trato comercial en la representación femenina: "The emphasis of this description is not upon prostitution, but upon sin, hedonism, and immoderate excess" (1997, p. 50), aunque Francomano matiza esta aserción al rastrear los términos económicos y de intercambio comercial que tanto literal como simbólicamente recorren el poema (2014). A pesar de que es cierto que el principio del poema refuerza claramente el pecado como base de la prostitución como oficio, lo que no resulta extraño según la orientación y base hagiográfica innegable de la historia de esta pecadora arrepentida, lo que se aprecia es la integración de pecado y delito a partir de la idea de marginalidad.

El carácter marginal de la existencia de María como prostituta queda claro, en este sentido, en la distinción espacial como autoexclusión: "allá va prender ostal / con las malas en la cal" (149-150). Esa marginalidad revela su impronta verdaderamente antisocial en su asociación con la muerte o el peligro de muerte que conlleva la conducta de la pecadora. Lo que debiera considerarse bajo el espectro del placer y del deseo de los jóvenes que la pretenden ("porque fiziessen su plazer; / e por fer todo su viçio / los mantenié a grant deliçio", 162-164) adquiere en el poema una relación con la muerte como única conclusión posible del pecado; si se escapa del orden social o se está fuera de él, la muerte se concibe cercana, como se detalla en la sucesión de las disputas incontrolables que provoca el pecado como quebrantador del orden social:

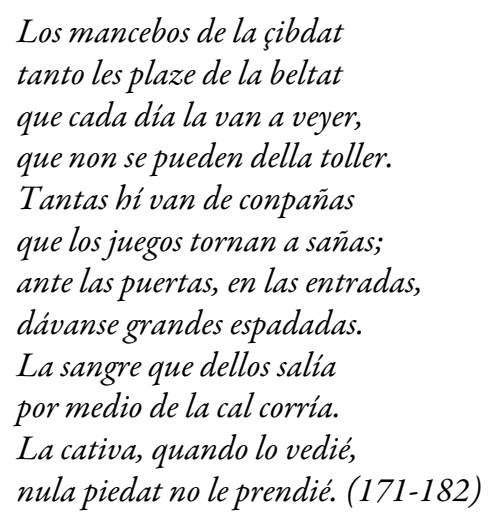

La segunda parte del poema, la etapa penitencial de la vida de María Egipciaca, se inicia con el arrepentimiento de la pecadora en Jerusalén, en la festividad de la Ascensión de la Virgen, y supone tanto el triunfo del bien sobre el mal como de lo comunitario sobre lo individual. Ese triunfo está representado en la propia trayectoria vital de María Egipciaca, en principio, y supone la anulación del yo bajo la forma de la penitencia para alcanzar la redención; se manifiesta de manera privilegiada más tarde, sin embargo, en los monjes de la abadía de San Juan que avalan tanto textual como doctrinalmente la santidad de la penitente. 
En la oración que María de Egipto le dirige a la Virgen y que verbaliza su arrepentimiento por su vida anterior de pecado, parte importante del reconocimiento de ese pasado es la naturaleza individual del mal, que se resalta a través del “yo” mediante el cual María de Egipto se declara del todo opuesta a la Virgen:

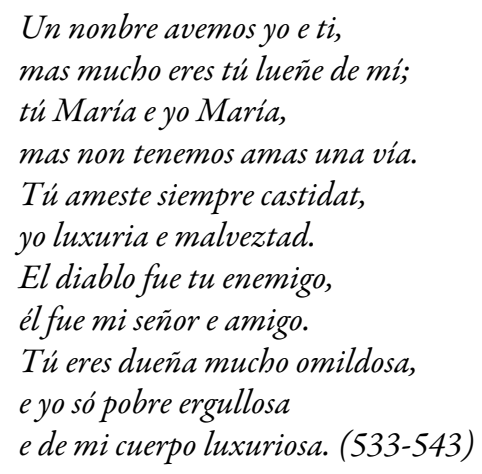

La anulación de la individualidad, necesaria para concretar como penitencia la renuncia al pecado verbalizada en esta oración, asume en María de Egipto un carácter marcadamente femenino, como si su ser individual se condensara esencialmente en su ser mujer. De esta forma, la penitencia en el desierto la convierte casi en un animal, resaltándose sobre todo la pérdida de sus atributos femeninos como parte de su ascenso espiritual: ya no posee los atavíos que la distinguían como mujer ("toda se mudó d'otra figura, / qua non ha paños nin vestidura”, 720-721), desaparece su carnadura femenina ("perdió las carnes e la color, / que eran blancas como la flor", 722-723), todo su rostro se opaca y arruga ("la faz muy negra e arrugada / de frío viento e elada”, 732-733), ya no tiene tetas ("en sus pechos non avía tetas, / como yo cuido eran secas", 738-739), su vientre se seca ("el vientre avié seco mucho, / que non comié nengún conducho", 744-745) y toda ella se vuelve alguien ya indistinguible sexualmente, lo que queda claro una vez que el monje Gozimás la descubre en medio de su propia estancia penitente: "vio la sombra veramiente; / sombra vio que era / de omne o de fembra" (931-933).

A pesar de perder cada uno de los atributos y condiciones de su feminidad, la virtud en María de Egipto no asume un signo comunitario hasta el momento de su muerte y la ratificación de su santidad, justamente por su carácter de anacoreta. Esa impronta comunitaria se concentra en el texto, en cambio, en la carga doblemente positiva y socialmente avalada de los monjes de la abadía de San Juan, en tanto hombres y en tanto religiosos. Esos monjes, que constituyen en el poema la medida acabada del bien, se perciben ya en su primera descripción antes como un grupo que como individuos particulares: el poeta los presenta como un todo desde el inicio ("contarvos é de una abadía / que era en cabo de la montaña / e havía hí buena conpaña”, 799-801); no se los individualiza ("mas nunqua viestes una gente / que a Dios serviés' tan gente", 802-803), porque ellos mismos han perdido su individualidad al renunciar a las posesiones materiales y a las comodidades humanas ("ni yazen en lechos ni en cameñas; / por alimpiarse de sus pecados / non calçavan çapatos”, 807-809). La pérdida de su individualidad supone la ausencia de pecado: "Entr'ellos non avié copdiçia, / ni enbidia nin avaricia" (824-825), y en este contexto Gozimás solo resulta el referente de un colectivo que testimonia la penitencia de María Egipciaca y, al hacerlo, la integra a una congregación santa que remite, en definitiva, a la Iglesia como comunidad cristiana.

\section{Figuras triádicas del bien en el Libro de LOS tres reYes de OrIENTE}

En el Libro de los tres reyes de Oriente se reitera la tríada identificada con el bien, como sucedía en el Libro de Apolonio, pero se triplica su impronta en esta última historia del códice K-III-4, abarcando a todas las figuras principales del poema. Esto es llamativo si se considera la extensión ínfima del texto en comparación con los otros dos poemas que integran el manuscrito, lo que reafirma el cuidado estructural de la historia y 
la dinámica composicional unitaria cuestionada sin embargo por la crítica temprana. En efecto, fue Fradejas Lebrero en 1957 quien sentó la agenda crítica posterior al plantear que "dos partes, yuxtapuestas ó inhabilmente ligadas forman el poema" (1957, p. 144), consideración basada en la narración inicial de la Adoración ligada básicamente con lo referido en los evangelios canónicos y el episodio siguiente del asalto de los ladrones vinculado, en cambio, a relatos apócrifos. ${ }^{11}$

El primer terceto positivo del poema comprende a los Reyes Magos. Estos personajes resultan la representación inicial del bien en el poema, y su figura incluso se anticipa, previo al comienzo del texto, ya en la ilustración del folio $82 \mathrm{v}$ como apertura del poema en la disposición manuscrita. Su relevancia es tal que el título de la historia en el códice refiere directamente a ellos (Libre dels tres reys d'Orient), a pesar de que el relato en verdad se concentra en un episodio de la infancia de Jesús proveniente de los evangelios apócrifos: el asalto de unos ladrones a la Sagrada Familia en su huida a Egipto. La Adoración se presenta como un reconocimiento conjunto de la naturaleza de Cristo, y la figura de cada mago solo se individualiza por los dones que le ofrecen al recién nacido; esos dones, y su propia figura individual, en este sentido, son funcionales a la consideración de la naturaleza de Jesús como rey, como hombre y como divinidad, por lo que en verdad constituyen una singularización aparente de una unidad en sí misma indisoluble:

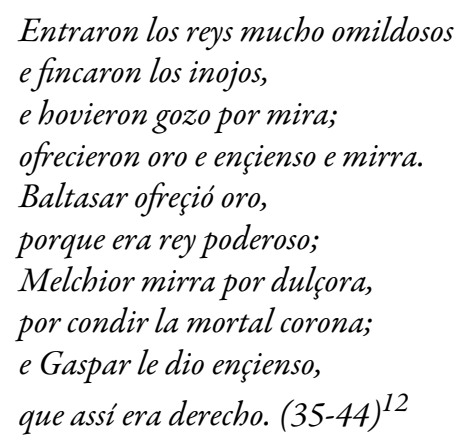

A los Reyes Magos como representación del bien plural se opone la figura singular de Herodes como ideal acabado de la maldad. Su individualidad está resaltada por ser un personaje histórico que ve amenazado su poder personal y, como respuesta a esa amenaza, no hace otra cosa que asesinar a todos los posibles oponentes de ese poder solo por compartir la edad cronológica de Jesús, en el episodio bíblico conocido como la matanza de los inocentes.

La Sagrada Familia se presenta como el segundo terceto relevante en el poema y la manifestación cabal del bien, aquella avalada por la Escritura según deja conocer la voz del ángel al instar a José a la partida hacia Egipto: "Dixo: 'Lieva, varón, e ve tu vía, / fuye con el niño e con María; / vete para Egipto, / que así lo manda el escripto”" (86-89).

Los ladrones, por su parte, constituyen la representación del mal que se opone a la Sagrada Familia al asaltarla en el desierto. A pesar de ser dos, pronto se da la distinción entre ambos, ya que uno será efectivamente malvado en tanto el otro buscará preservar la vida de los asaltados. En el Evangelio árabe de la infancia, además, los ladrones que asaltaban a Jesús, María y José pertenecían a un grupo amplio, solo que eran quienes estaban despiertos mientras el resto dormía; la adaptación hispánica del episodio privilegia, en cambio, lo singular frente a lo colectivo como encarnación maligna.

La familia del ladrón bueno, en último lugar, condensa el carácter unitario de la manifestación del bien en el Libro de los tres reyes de Oriente, al tiempo que refuerza la constitución familiar como núcleo básico del orden social. Resulta significativo, particularmente en este último caso, cómo el mal singular se reconstruye positivamente en el entorno familiar, ya que la presencia del delito -en este caso del robo- no impide el milagro de sanación del hijo de este ladrón, ni su presencia en el Calvario siendo él mismo también ladrón en su adultez, sino que sienta las bases de la redención salvífica a través de la posibilidad de perdón del pecado. 
En la familia del buen ladrón, el lugar determinante será el de la esposa de este malhechor, en tanto protagonista del milagro de sanación de su hijo por el agua del baño de Cristo; milagro concretado por la gracia mariana, en principio, pero también propiciado por su generosidad y servicio desinteresado a la Sagrada Familia. Resulta interesante, en este sentido, la cohesión que también se da en el poema entre las mujeres, aunque concentrándose especialmente en su figura como madres, en una identificación con la Virgen María como madre santa. Esta consideración de la identidad femenina supeditada a lo materno está presentada inicialmente en el poema ya en la referencia a la maldad de Herodes, debido a que frente a su perversidad personal se narra el dolor de las madres de los santos inocentes como representación de esta naturaleza femenina enfocada maternalmente: "Mesquinas, iqué cuitas vieron / las madres que los parieron! / Toda madre puede entender / quál duelo podrié seyer, / que en el çielo fue / oído el planto de Rachel” (66-71).

En la estructura triplicada del mal opuesto al bien del Libro de los tres reyes de Oriente, el bien resulta siempre una fuerza cohesiva, anclada sobre todo en la virtud de la familia como estructura determinante del orden social, que remite en última instancia a la representación de la Iglesia como familia cristiana; por el contrario, el mal se revela en cada caso como una amenaza singular.

\section{A MODO DE CONCLUSIón}

La oposición bien-mal, que en la Edad Media es el eje tanto estructural como simbólico de muchos relatos ejemplares, adquiere mayor relevancia cuando se aprecia no solo en textos específicos, sino en la dinámica constitutiva de manuscritos antológicos, como el escurialense K-III-4 que, en su composición, revelan lo significativo de esa contraposición que se transmite ya no solo de manera singular, sino de forma conjunta. En este sentido, la transmisión codicológica aunada de una oposición esencial para gran parte de la literatura medieval, en especial la asociada al movimiento de clerecía que domina gran parte de la escena castellana de principios del siglo XIII, también da cuenta de una orientación plural unitaria por encima de la singularidad textual.

En relatos en los cuales la impronta cristiana es importante, como el Libro de Apolonio, o directamente determinante como la Vida de Santa María Egipciaca y el Libro de los tres reyes de Oriente, esa contraposición entre el bien y el mal adquiere matices comunitarios más profundamente asociados al mantenimiento de un orden social estable o que intenta procurarse como permanente, que permite distinguir manifestaciones grupales del bien frente a expresiones de la maldad asociadas tanto al pecado como a la individualidad y su condición marginal.

Específicamente en cuanto a esas manifestaciones del mal, el pecado individual se identifica básicamente con lo femenino, a través del énfasis en la lujuria como pecado asociable a la mujer y a su condición. La consideración de la individualidad en su carácter marginal se plantea inicialmente en el Libro de Apolonio a través del pecado del incesto que involucra al rey Antíoco y a su hija, a pesar de ser uno victimario y la otra víctima. En la Vida de Santa María Egipciaca, la temática se desarrolla ya de forma acabada, ocupando toda la primera parte de la historia de la mujer como prostituta. En el último poema del códice, el Libro de los tres reyes de Oriente, el carácter marginal de la individualidad no se asocia concretamente a lo femenino, tal vez por la impronta mariana determinante del poema; sí se reitera, en cambio, en figuras del mal concebidas como oponentes directos de Cristo y su redención salvífica.

Las manifestaciones del bien, de manera contraria, se destacan por su conformación unificada frente a lo individual. La familia protagonista del Libro de Apolonio funciona de manera unitaria a pesar de estar separada de hecho en gran parte de la historia, mediante la identificación de la virtud cristiana como parámetro de conducta comunitario. En la Vida de Santa María Egipciaca, esa impronta comunitaria está representada por la abadía de San Juan como institución cristiana que integra la santidad femenina de la anacoreta al reconocer y testimoniar su historia. La Sagrada Familia del Libro de los tres reyes de Oriente está enfocada sobre todo a partir de la figura mariana, promotora del milagro de sanación del hijo del buen ladrón y quien unifica, a lo 
largo del poema, tanto a las madres de los santos inocentes asesinados por Herodes como a la esposa del buen ladrón, a través de su figura femenina identificada esencialmente como figura materna.

La asociación de la mujer con la función materna del último poema del Ms. K-III-4 de todas formas tampoco constituye una reivindicación femenina, ya que al centralizar la medida del bien frente al mal en su rol maternal -en especial a través de la identificación de la figura femenina con la Virgen María- se continúa reduciendo lo femenino o marginándolo a una única funcionalidad que necesita ser integrada familiar y socialmente para volverse una manifestación plural de lo bueno. Las representaciones colectivas del bien en el contexto del códice K-III-4, de esta manera, deudoras de la ética cristiana de gran parte de la literatura de naturaleza clerical de la primera mitad del siglo XIII, se configuran en cada poema particular, pero se resignifican a través de una transmisión codicológica asimismo colectiva en tanto ideales unificados que promueven la unificación social como alternativa privilegiada frente a la maldad y el pecado individual.

\section{REFERENCIAS}

Alvar, M. (Ed.). (1965). Libro de la infancia y muerte de Jesús (Libre dels tres reys d'Orient). Madrid: CSIC.

Arizaleta, A. (2000). La transmisión del saber médico: Libro de Alexandre y Libro de Apolonio. En M. Freixas y S. Iriso (Eds.), Actas del VIII Congreso Internacional de la Asociación Hispánica de Literatura Medieval (Santander, 22-26 de septiembre de 1999) (pp. 221-231). Santander: Consejería de Cultura del Gobierno de Cantabria.

Beresford, A. M. (1997). "Encendida del ardor de la luxuria": Prostitution and Promiscuity in the Legend of Saint Mary of Egypt. En A. M. Beresford (Ed.), "Quien hubiese tal ventura": Medieval Hispanic Studies in Honour of Alan Deyermond (pp. 45-56). London: Department of Hispanic Studies, Queen Mary and Westfield College.

Brownlee, M. S. (1983). Writing and Scripture in the Libro de Apolonio: The Conflation of Hagiography and Romance. Hispanic Review, 51(2), 159-174.

Chaplin, M. (1967). The Episode of the Robbers in the Libre dels tres reys d'Orient. Bulletin of Hispanic Studies, 44, $88-95$.

Cuesta Torre, M. L. (1997). Uso del poder y amor paternal en el Libro de Apolonio. En J. M. Lucía Megía (Ed.), Actas del VI Congreso Internacional de la Asociación Hispánica de Literatura Medieval (Alcalá de Henares, 12-16 de septiembre de 1995) (vol. 1, pp. 551-560). Alcalá de Henares: Universidad de Alcalá.

Cuesta Torre, M. L. (1999). La muerte aparente: Un episodio del Libro de Apolonio. Livius, 13, 9-21.

Desing, M. V. (2011). Luciana's story: Text, Travel, and Interpretation in the Libro de Apolonio. Hispanic Review, $79(1), 1-15$.

Deyermond, A. (1989). Emoción y ética en el Libro de Apolonio. Vox Romanica, 48, 153-164.

Fradejas Lebrero, J. (1957). El Evangelio árabe de la infancia y Lo Libre dels tres Reys d'Orient. Tamuda, 5, 144-149.

Francomano, E. C. (2014). "Taking the Gold Out of Egypt": Prostitution and the Economy of Salvation in the Vida de Maria Egipciaca. Hispanic Review, 82(4), 397-420.

Lacarra, M. J. (1988). Amor, música y melancolía en el Libro de Apolonio. En V. Beltrán (Ed.), Actas del Congreso de la Asociación Hispánica de Literatura Medieval (pp. 369-379). Barcelona: PPU.

Morreale, M. (1991-92). Oración litúrgica y oración personal en la Edad Media: Libro de Apolonio, estrofas 376-85. Boletin de la Real Academia de Buenas Letras de Barcelona, 43, 165-170.

Musgrave, J. C. (1976). Tarsiana and Juglaría in the Libro de Apolonio. En A. Deyermond (Ed.), Medieval Hispanic Studies Presented to Rita Hamilton (pp. 129-138). London: Tamesis.

Richardson, V. (1984). Structure and Theme in the Libre dels tres reys d'Orient. Bulletin of Hispanic Studies, 61, 183-188.

Robertson, D. (1980). Poem and Spirit. The Twelfth-Century French Life of saint Mary the Egyptian. Medioevo Romanzo, 7(3), 305-327.

Segura Graiño, C. (2001). Las mujeres en la organización familiar. En J. I. de la Iglesia Duarte (Coord.), La familia en la Edad Media. XI Semana de Estudios Medievales (pp. 209-220). La Rioja, España: Instituto de Estudios Riojanos. 
Surtz, R. E. (1980). The Spanish Libro de Apolonio and Medieval Hagiography. Medioevo Romanzo, 7, 328-341.

Zubillaga, C. (2014). Poesía narrativa clerical en su contexto manuscrito. Estudio y edición del Ms. Esc. K-III-4 ("Libro de Apolonio", "Vida de Santa María Egipciaca", "Libro de los tres reyes de Oriente"). Buenos Aires: SECRIT.

Zubillaga, C. (2016). Biografía y dimensión humana en el Libro de los tres reyes de Oriente. Bulletin of Hispanic Studies, 93(8), 843-854.

Zubillaga, C. (2019). La voz de las mujeres en el Libro de Apolonio. Mirabilia, 29(2), 13-28.

\section{Notas}

1 Aunque el Libro de Apolonio, la Vida de Santa Maria Egipciaca y el Libro de los tres reyes de Oriente son poemas fechables a comienzos del siglo XIII, el manuscrito es de fines del siglo XIV, por lo que su compilación conjunta da cuenta de una tarea previa de reunión de esas historias en el códice y de una relectura compilatoria acorde al paso del tiempo.

2 Son esas virtudes presentes en la familia protagonista de la historia las que han llevado a la crítica especializada a resaltar los componentes cristianos de la historia, aunque enfocándose particularmente en la figura de Apolonio. Ver al respecto, especialmente, los aportes de Surtz (1980) y Brownlee (1983).

3 Acerca de este desempeño de Tarsiana como juglaresa, ver Musgrave (1976).

4 Desing (2011) postula la figura de Luciana, en este sentido, como más relacionada con la palabra escrita que la del propio Apolonio.

5 Las citas del Libro de Apolonio corresponden a la edición conjunta del Ms. K-III-4 de Zubillaga (2014), indicándose a continuación de cada una el número de estrofas y/o versos correspondientes.

6 Esta vinculación es resaltada, entre otros, por Lacarra (1988), Morreale (1991-92) y Zubillaga (2019).

7 Las relaciones familiares más cercanas, en especial la de padre-hija, resultan fundamentales en todo el poema y su desarrollo, a partir de situaciones que se repiten directamente o como ecos posibles de esas relaciones, como analizan detalladamente en especial Deyermond (1989) y Cuesta Torre (1997).

8 De acuerdo con Cuesta Torre, el detalle del proceso de curación de Luciana y la atención al saber médico "podría indicar la pertenencia del autor a este estamento, o al menos su relación con él” (1999, p. 19). Arizaleta, por su parte, poniendo en relación el saber médico en el Libro de Alexandre y el Libro de Apolonio, destaca que "todo indica que sus autores no practicaban la medicina, sino que poseían como letrados ciertos conocimientos de esa ciencia” (2000, p. 231).

9 Las citas de la Vida de Santa María Egipciaca corresponden a la edición conjunta del Ms. K-III-4 de Zubillaga (2014), indicándose a continuación de cada una el número de versos correspondientes.

10 La cita de la Vie de Sainte Marie l'Égyptienne corresponde a la edición de Baker (1916-17). Acerca de este poema francés, que inicia la vertiente oriental de la leyenda de la prostituta arrepentida, ver Robertson (1980).

11 Los principales estudiosos posteriores del Libro de los tres reyes de Oriente retomaron esta afirmación de Fradejas Lebrero, para cuestionarla y ahondar en la unidad tanto estructural como doctrinal del poema: Alvar (1965), Chaplin (1967), Richardson (1984) y Zubillaga (2016).

12 Las citas del Libro de los tres reyes de Oriente corresponden a la edición conjunta del Ms. K-III-4 de Zubillaga (2014), indicándose a continuación de cada una el número de versos correspondientes. 